\title{
Inspiratory Muscle Training and Arterial Blood Oxygen Saturation in Patients With Chronic Obstructive Pulmonary Disease
}

\author{
Maryam Bakhshandeh Bavarsad ${ }^{1, *}$; Abdolali Shariati ${ }^{2}$; Esmaiel Idani ${ }^{3}$; Hamideh Zaheri ${ }^{4}$; \\ Sayed Mahmood Latifi ${ }^{5}$ \\ ${ }^{1}$ Department of Nursing, School of Nursing and Midwifery, Lorestan University of Medical Sciences, Khorramabad, IR Iran \\ ${ }^{2}$ Department of Nursing, School of Nursing and Midwifery, Ahvaz Jundishapur University of Medical Sciences, Ahvaz, IR Iran \\ ${ }^{3}$ Department of Internal Medicine, School of Medicine, Ahvaz Jundishapur University of Medical Sciences, Ahvaz, IR Iran \\ ${ }^{4}$ Department of Midwifery, School of Nursing and Midwifery, Ahvaz Jundishapur University of Medical Sciences, Ahvaz, IR Iran \\ 5 Department of Midwifery, School of Nursing and Midwifery, Ahvaz Jundishapur University of Medical Science, \\ ${ }^{*}$ Corresponding author: Maryam Bakhshandeh Bavarsad, Department of Nursing, School of Nursing and Midwifery, Lorestan University of Medical Sciences, Khorramabad, IR Iran. \\ Tel:+98-9132336561, E-mail: bavarsad.maryam@yahoo.com
}

Received: August 5, 2014; Revised: October 20, 2014; Accepted: December 28, 2014

\begin{abstract}
Background: One of the problems of the patients with chronic obstructive pulmonary disease (COPD) is the weakness of the respiratory muscles that causes oxygen desaturation at rest and activity and decreases exercise tolerance.

Objectives: This study aimed to investigate the effect of inspiratory muscle training on arterial oxygen saturation $\left(\mathrm{SPO}_{2}\right)$.

Patients and Methods: Forty patients with mild to very severe COPD were recruited for this study, which is a randomized control trail. The patients were randomized to IMT (inspiratory muscle training) and control group. Training was performed with Respivol (a kind of inspiratory muscle trainer) for 8 weeks ( $15 \mathrm{~min} / \mathrm{d}$ for $6 \mathrm{~d} /$ week). SPSS software version 16 was used to analyze the data by performing independent $t$ test, paired t test, and Fisher exact test.

Results: Results showed that, after 8 weeks of inspiratory muscle training, there was a little increase (but not statistically significant improvement) in $\mathrm{SPO}_{2}$ (from $92.6 \pm 8.71 \%$ to $95.13 \pm 7.08 \%$, with $\mathrm{P}=0.06$ ), whereas it remained unchanged in the control group (from $96.0 \pm$ $3.46 \%$ to $96.4 \pm 3.35 \%$ with $\mathrm{P}=0.51)$. No statistically significant difference was seen between the two groups $(\mathrm{P}>0.05)$.

Conclusions: Although inspiratory muscles training can prevent desaturation, which is caused by activity, it fails to improve it.

Keywords:Pulmonary; Rehabilitation; Respiratory Muscle Training; Pulmonary Disease, Chronic Obstructive; Arterial Oxygen Saturation; Pulse Oximetry
\end{abstract}

\section{Background}

The American Thoracic Society defines chronic obstructive pulmonary disease (COPD) as "a disease process that is progressive chronic airway limitation due to chronic bronchitis, emphysema, or both" (1). According to statistics reported by the World Health Organization, there are 80 million people with chronic obstructive pulmonary disease worldwide (2); of them 12 million live in the United States (3). Iran's statistics show that, on average, $10 \%$ of people are affected by chronic obstructive pulmonary disease (COPD), but the amount varies from $1 \%-40 \%$ in different communities with different climatic conditions (4).

The disease incurs more than $\$ 30$ million for the health system. In this context, disability-adjusted years (DALYs) are considered as a measure of being cost-intensive, and COPD will climb from the eleventh factor in 2002 to the seventh factor in 2030 (5). These patients suffer from many problems, including dyspnea, exercise limitation, reduced quality of life, poor airway clearance, lack of ef- fective breathing pattern, impaired gas exchange, cyanosis, cough, sputum, sleep and eating patterns disruption due to dyspnea, feeling of uncertainty, pain, and changes in body image (6-8).

As a comprehensive care plan is needed for patients from COPD, pulmonary rehabilitation programs are considered to boost the treatment program, control symptoms, and enhance the practical capacity in these patients (9). Recent studies show that pulmonary rehabilitation leads to improvement in exercise tolerance, quality of life, daily functioning, psychosocial and cognitive functioning, as well as an increase in the sense of self-control and improvement in capillary density in the muscles under exercise, which can result in fewer hospital admissions, bed days, the need for health care services, patient dependency, dyspnea and fatigue, and can reduce lactic acid, minute ventilation, and heart rate (10-14).

There are conflicting results on the effects of various

Copyright (C) 2015, Ahvaz Jundishapur University of Medical Sciences. This is an open-access article distributed under the terms of the Creative Commons Attribution-NonCommercial 4.0 International License (http://creativecommons.org/licenses/by-nc/4.0/) which permits copy and redistribute the material just in noncommercial usages, provided the original work is properly cited. 
methods of pulmonary rehabilitation, especially pursed lip breathing and diaphragmatic breathing, regarding the level of arterial oxygen saturation (15-17). Inspiratory muscle training (IMT) is one of the pulmonary rehabilitation methods (8) that a few studies have been done on its effects on the arterial blood oxygen saturation level and respiratory rate of patients with COPD. As the American College of Chest Physicians and the American Association of Cardiovascular and Pulmonary Rehabilitation committee (ACCP/AACVPR) have suggested that a large-scale, multicenter randomized controlled trial (RCT) should be performed with appropriate statistical power to better examine the role of IMT in treating patients with COPD (18), the researchers were intended to examine the effect of this pulmonary rehabilitation method on the arterial blood oxygen saturation level and respiratory rate in patients with COPD.

\section{Objectives}

This study aimed to investigate the effect of inspiratory muscle training on arterial oxygen saturation $\left(\mathrm{SPO}_{2}\right)$.

\section{Patients and Methods}

This study was a randomized clinical trial, performed on 40 patients with COPD referred to specialized pulmonary clinic of Aria Hospital in Ahvaz. Sampling procedure lasted for 5 months, and 40 patients who met the inclusion criteria were selected out of 72 patients. Then they were divided into inspiratory muscle training group (18 males and 2 females) and control group (19 males and 1 female), using simple random method. The following statistical equation was used to determine sample size. To increase the accuracy of the study, the number of samples in each group was increased to 20 (Equation 1).

$$
\text { Equation 1. } \quad n=\frac{\left(Z_{1-\frac{\alpha}{2}}+Z_{1-\beta}\right)^{2}\left(S_{1}^{2}+S_{2}^{2}\right)}{\left(X_{1}^{-}-X_{2}^{-}\right)^{2}}=15
$$

$\alpha=0.05 ; \beta=0.2 ; S_{1}=17.3 ; S_{2}=15.8 ; X_{1}^{-}=66.1 ; X_{2}^{-}=48.5$

Patients with spirometric evidence of significant chronic airflow limitation ( $\mathrm{FEV} 1 / \mathrm{FVC}<70 \%$ predicted) manifesting mild to very severe COPD symptoms, according to the GOLD criteria (19), and in the age range of 45 - 65 years, were enrolled. The patients with a BMI $>35$, history of underlying diseases such as diabetes, musculoskeletal disorders, cardiovascular diseases, and neurological diseases that affect the results of 6-min walking test (6 MWT) were excluded (20). Finally, 40 patients (37 males and 3 females) were selected based on inclusion and exclusion criteria, and the above study was performed after obtaining their consent and permission from Ahvaz Jundishapur University of medical sciences.

In this study, a type of flow-volumetric inspiratory exerciser, called Respivol ${ }^{\circledR}$ (Medinet, Italy) was used, which consists of two chamber-like cylinders, within each of them, a floating indicator is located. In the graduated cylinder, the floating indicator shows the total inspiratory volume, while indicator in flow cylinder shows the patient the time when sufficient inspiratory flow is established $(21,22)$. In the first session, patients were taught to use the device, and the amount of their inspiratory volume was marked on the device, and achieving greater inspiratory volume was considered as the target level. Training was performed for 8 weeks (15 minutes/day for 6 days/week) at home. During these 8 weeks, patients were followed up with phone calls. At the beginning and at the end of these eight-week period, initial data were collected from all patients, and 6-min walking test (6 MWT) was obtained from all patients according to the protocol provided by the American Thoracic Society (ATS). In this test, the activity intended for patients included walking for 6 minutes on a flat surface, which was done under the supervision of a therapist. Patients were encouraged to walk for $6 \mathrm{~min}$ utes until the target heart rate (age in terms of years -200) was obtained or the activity was limited because of dyspnea and fatigue (20). At the end of the 6-minute walk, the level of arterial oxygen saturation was evaluated by pulse oximeter (NONIN, Ganshorn, USA). Finally, the data were analyzed by SPSS16 software. Paired t-test, independent t-test, and Fisher exact test were used for statistical analysis.

\subsection{Ethical Considerations}

This study was conducted after obtaining the confirmation of the Ahvaz Jundishapur Ethics Committee and the informed consent from all subjects participating in the study (ruling number: U89295).

\section{Results}

The study results showed that $86.7 \%$ of the participants in inspiratory muscle training group and $93.3 \%$ of cases in the control group were male. Since the duration of the disease in the intervention and control groups were 4 and 5.8 years, respectively, the two groups were similar in this respect. At the beginning of the study, there were no statistically significant differences between the two groups in terms of the variables of age, sex, body mass index, pack/year, disease severity and the number of smokers and non-smokers $(\mathrm{P}>0.05)$ (Table 1).

After examining the post-exercise $\mathrm{SPO}_{2}$ level [6-min walking test, according to the protocol provided by the American Thoracic Society (ATS)] (20), a slight but nonsignificant increase (from $92.6 \pm 8.71 \%$ to $95.13 \pm 7.08 \%$, with $\mathrm{P}=0.06$ ) in oxygen saturation was observed in the inspiratory muscle training group after 8 weeks, whereas it remained unchanged in the control group (from 96.0 $\pm 3.46 \%$ to $96.4 \pm 3.35 \%$ with $P=0.51$ ). Furthermore, there was no statistically significant difference between the two groups $(\mathrm{P}=0.13)$ (Table 2). 
Bakhshandeh Bavarsad M et al.

\begin{tabular}{|c|c|c|c|}
\hline $\begin{array}{l}\text { Demographic } \\
\text { Factor }\end{array}$ & IMT $^{\mathrm{b}}$ & Control & PValue \\
\hline Age, y & $58.8 \pm 6.82$ & $54.2 \pm 8.09$ & $P=0.103$ \\
\hline BMI, kg/m² & $24.88 \pm 5.02$ & $24.97 \pm 4.72$ & $P=0.95$ \\
\hline $\begin{array}{l}\text { Gender, Male/ } \\
\text { Female }\end{array}$ & $13 / 2$ & $14 / 1$ & $P=1.0$ \\
\hline $\begin{array}{l}\text { Smoker/ } \\
\text { Nonsmoker, No. }\end{array}$ & $11 / 4$ & $11 / 4$ & $P=1.0$ \\
\hline Pack/Year, No. & $26.39 \pm 28.45$ & $30.36 \pm 51.42$ & $P=0.79$ \\
\hline Disease severity & $2.13 \pm 1.35$ & $1.93 \pm 1.21$ & $P=0.81$ \\
\hline
\end{tabular}

Table 2. Comparison of $\mathrm{SPO}_{2}$ Preintervention and Postintervention Among two Groups ${ }^{a, b}$

\begin{tabular}{lccc}
\hline & \multicolumn{1}{c}{ IMT } & Control & PValue \\
\hline $\begin{array}{l}\mathrm{SPO}_{2} \text { before } \\
\text { training,\% }\end{array}$ & $92.60 \pm 8.71$ & $96.00 \pm 3.46$ & $\mathrm{P}=0.17$ \\
$\begin{array}{l}\mathrm{SPO}_{2} \text { after } \\
\text { training,\% }\end{array}$ & $95.13 \pm 7.08$ & $96.40 \pm 3.35$ & $\mathrm{P}=0.53$ \\
\hline $\begin{array}{l}\text { a Values are expressed as Means } \pm \mathrm{SD} . \\
\text { b Abbreviation: } \mathrm{SPO}_{2}, \mathrm{O}_{2} \text { saturation. }\end{array}$ & & \\
\end{tabular}

\section{Discussion}

COPD, which directly affects the lungs, can lead to systemic complications, including respiratory and peripheral muscle dysfunction. With regard to the pathophysiology of respiratory muscle dysfunction, it can be said that the poor inspiratory muscle function is the result of structural changes in the thorax and diaphragm, followed by hyperinflation, potential structural changes in the muscle and the effect of systemic factors. Recent evidence suggests a fundamental defect in the flexibility of diaphragm fibers in COPD patients (10). Such a defect can cause respiratory muscle weakness, which consequently leads to shallow breathing (9) and in turn reduces the level of arterial blood oxygen saturation.

In the study by Ramos et al. it was found that the level of arterial oxygen saturation increases during pursed lip breathing (15). In the study by Faager et al. in 2008, it was also shown that pursed lip breathing during the shuttle test increases the amount of distance traveled by patients with COPD. Although these patients undergo a decrease in arterial oxygen saturation during walking, the decrease was $1.2 \%$ less than that in those who did not use the pursed lip breathing during activity (16). In a study by Izadi Oonji et al. it was shown that pursed lip breathing at rest can increase arterial oxygen saturation, which is maintained for one hour after training (9). Petty's study showed that breathing retraining techniques such as diaphragmatic breathing and pursed lip breathing have no effect on $\mathrm{PaO}_{2}$ (23). In the study by Hill et al. a slight but non-significant increase was observed in the $\mathrm{SPO}_{2}$ level of patients with COPD after 8 weeks of high-intensity inspiratory muscle training, while in the low-intensity inspiratory muscle training group, a slight and non-significant decrease was observed in the $\mathrm{SPO}_{2}$ level (24). In the study by Chawla et al. it was shown that the level of arterial oxygen saturation had a significant increase after inspiratory muscle training. It should be noted that in this study, the oxygen saturation level was calculated at rest (25). Based on the results of various studies and this study, we conclude that, although in studies of pursed lip breathing, an increase can be seen in arterial oxygen saturation after exercise, this increase was observed immediately after pursed lip breathing, and therefore appears to be related to the hyperventilation, rather than inspiratory muscle strength. As it was seen in the study of Faager, pursed lip breathing during activity does not increase the level of arterial oxygen saturation, but actually reduces the $\mathrm{SPO}_{2}$ level (16).

It should be noted that the rate of decline in this group was less than that of the control group, while in the study of Hill et al. (24) and this study, inspiratory muscle training not only caused a decrease in arterial oxygen saturation, but also a slight and nonsignificant increase occurred, showing that inspiratory muscle training actually prevents a drop in $\mathrm{SPO}_{2}$ in patients with COPD through inspiratory muscle strength (instead of hyperventilation), and consequently will increase the tolerance of these patients to activity. It is also noteworthy that, based on the oxyhemoglobin dissociation curve, changes of $\mathrm{SPO}_{2}$ are less than those of $\mathrm{PaO}_{2}$. As a result, if $\mathrm{PaO}_{2}$ was used instead (for the study), perhaps significant changes would be observed. Since respiratory problems occur more in severe state of the disease, the effects of inspiratory muscle training would seem to be better characterized if patients with severe and very severe degree were selected. Accordingly, to clarify further the effects of this type of breathing exercises, additional studies are recommended by removing the limitations mentioned in this research.

The results of this study show that, although inspiratory muscle training does not increase the $\mathrm{SPO}_{2}$ level after exercise in patients with chronic obstructive pulmonary disease, it prevents a decrease in $\mathrm{SPO}_{2}$ level after exercise, and, therefore, can lead to an increase in exercise tolerance in these patients. Consequently, it seems that nurses and physiotherapists should teach this simple method of pulmonary rehabilitation to the patients.

\section{Acknowledgements}

We thankfully acknowledge the financial and technical support of the Deputy of Research Affairs at Ahvaz Jundishapur University of Medical Sciences. Also we appreciate Khadije Moradbeigi and Rogayyeh Bagheri as well as Aria's Specialized Pulmonary Clinic staff for their 
valuable and sincere cooperation and patients for their participation in this study (Ruling number:U89295, IRCT code IRCT201104266299N1).

\section{Funding/Support}

This article has been supported by Ahvaz Jundishapur University of Medical Sciences.

\section{References}

1. Hevdari MR, Masjedi MR, Memarian R. Effects of rehabilitation techniques on the improvement of clinical status of COPD patients. PEJOUHANDEH. 2002;7(2):149-52.

2. Voll-Aanerud M, Eagan TM, Wentzel-Larsen T, Gulsvik A, Bakke PS. Respiratory symptoms, COPD severity, and health related quality of life in a general population sample. Respir Med. 2008;102(3):399-406.

3. Brunner L, Smeltzer SCO'C, Bare BG, Hinkle JL, Cheever KH. Brunner \& Suddarth's textbook of medical-surgical nursing.: Lippincott Williams \& Wilkins; 2010

4. Mirbagher A, Memarian R. The effects of rehabilitation techniques on the pulmonary function tests in moderate severity COPD patients. Horizon Med Sci. 2009;14(4):19-25.

5. Geddes EL, O'Brien K, Reid WD, Brooks D, Crowe J. Inspiratory muscle training in adults with chronic obstructive pulmonary disease: an update of a systematic review. Respir Med. 2008;102(12):1715-29.

6. Mirbagher AN, Rezaei M. The effects of pulmonary rehabilitation techniques on the clinical status of patients with moderate severity chronic obstructive pulmonary diseases (COPD) at university hospitals of Isfahan in 2006-7. J ZANJAN UNIV MED SCI HEALTH SERV. 2009;17(66):1

7. Mirbagheri N, Meamarian R, Mohammadi E. Effects of regular walking programme on quality of life of elderly patients with moderate COPD. Iranian J Nurs Res. 2007;6(6,7):19-27.

8. McConnell AK. The role of inspiratory muscle function and training in the genesis of dyspnoea in asthma and COPD. Prim Care Respir J. 2005;14(4):186-94.

9. Izadi Oonji F, Miranzadeh S, Afazel MR, Akbari H. The effect of breath training on arterial $\mathrm{O} 2$ sat and respiratory rhythms in patients with chronic obstructive pulmonary diseases. Sci J Kurdistan Unive Med Sci. 2006;11(3):35-43.

10. Celli B.R. . Pulmonary rehabilitayion in COPD. 2011. Available from: http://www.uptodate.com.

11. Vagaggini B, Costa F, Antonelli S, De Simone C, De Cusatis G, Martino $\mathrm{F}$, et al. Clinical predictors of the efficacy of a pulmonary rehabilitation programme in patients with COPD. Respir Med. 2009;103(8):1224-30.

12. Trappenburg JC, Troosters T, Spruit MA, Vandebrouck N, Decramer M, Gosselink R. Psychosocial conditions do not affect short-term outcome of multidisciplinary rehabilitation in chronic obstructive pulmonary disease. Arch Phys Med Rehabil. 2005;86(9):1788-92.

13. Rubi M, Renom F, Ramis F, Medinas M, Centeno MJ, Gorriz M, et al. Effectiveness of pulmonary rehabilitation in reducing health resources use in chronic obstructive pulmonary disease. Arch Phys Med Rehabil. 2010;91(3):364-8.

14. Mikelsons $\mathrm{C}$. The role of physiotherapy in the management of COPD. Resp Med: COPD Update. 2008;4(1):2-7.

15. Ramos EMC, Vanderlei LCM, Ramos D, Teixeira LM, Pitta F, Veloso M. Influence of pursed-lip breathing on heart rate variability and cardiorespiratory parameters in subjects with chronic obstructive pulmonary disease (COPD). Braz J Physical Ther 2009;13:288-93.

16. Faager G, Stahle A, Larsen FF. Influence of spontaneous pursed lips breathing on walking endurance and oxygen saturation in patients with moderate to severe chronic obstructive pulmonary disease. Clin Rehabil. 2008;22(8):675-83.

17. Mueller RE, Petty TL, Filley GF. Ventilation and arterial blood gas changes induced by pursed lips breathing. J Appl Physiol. 1970;28(6):784-9.

18. Ambrosino N. The case for inspiratory muscle training in COPD. For. Eur RespirJ. 2011;37(2):233-5.

19. GOLD workshop report.. global strategy for the diagnosis, management and prevention of chronic obstructive pulmonary disease. 2006. Available from: http://www.goldcopd.com.

20. A. T. S. Committee on Proficiency Standards for Clinical Pulmonary Function Laboratories.. ATS statement: guidelines for the six-minute walk test. Am J Respir Crit Care Med. 2002;166(1):111-7.

21. Battaglia E, Fulgenzi A, Bernucci S, Giardini ME, Ferrero ME. Home respiratory muscle training in patients with chronic obstructive pulmonary disease. Respirology. 2006;11(6):799-804.

22. Battaglia E, Fulgenzi A, Ferrero ME. Rationale of the combined use of inspiratory and expiratory devices in improving maximal inspiratory pressure and maximal expiratory pressure of patients with chronic obstructive pulmonary disease. Arch Phys Med Rehabil. 2009;90(6):913-8.

23. Petty TL. SUpportive therapy in copd. Chest. 1998;113(4 Supplement):256S-62S

24. Hill K, Jenkins SC, Philippe DL, Cecins N, Shepherd KL, Green DJ, et al.High-intensity inspiratory muscle training in COPD. Eur Respir J. 2006;27(6):1119-28.

25. Chawla S, Narwal R, Rawat J. Comparison of Inspiratory Muscle Training and Rib Raising Technique in Pulmonary Diseases Subjects. Indian J Physiother Occupational Ther. 2013;7(2):150-5. 